COMO CITAR ESTE ARTÍCULO:

García, C., Martínez, E. y Quintero, M. L. (2018). Exploratory factorial structure climate and labor flexibility. Revista de Antropología y Sociología: VIRAJES, 20(2). 55-72. DOI: 10.17151/rasv.2018.20.2.4.

\title{
Exploratory factorial structure climate and labor flexibility
}

\author{
CRUZ GARCÍA-LIRIOS* \\ ENRIQUE MARTÍNEZ-MUÑOZ** \\ MARÍA LUISA QUINTERO-SOTO***
}

Recibido: 7 mayo de 2018 Aceptado: 20 de junio de 2018

Artículo de Reflexión

\footnotetext{
** PhD in Complex Sciences. Centro de estudios Políticos y Sociales, Professor, Universidad Autónoma del Estado de México, Huehuetoca, México. E.mail: cgarcial213@profesor.uaemex.mx.

(1) ORCID: 0000-0002-9364-6796. Google Scholar

** $\mathrm{PhD}$ in Education. Universidad Autónoma del Estado de Hidalgo, Pachuca, México. E-mail: emmunoz@uaeh.edu.mx @ ORCID: 0000-0001-6418-5292. Google Scholar

** PhD Political Sciences. Universidad Autónoma del Estado de México, Nezahualcóyolt, México. E-mail: mlquinteros@uaemex.mx @ ORCID: 0000-0002-4198-550X. Google Scholar
} 


\begin{abstract}
Objective. Gross mode, the work climate has been studied as an area inherent in leadership. In the case of the one that is distinguished by its communication and vertical motivation, the work environment has been addressed as a determinant of flexibility in terms of conditions, salaries and benefits. In this regard, the objective of this paper has been to explore the dimensions of climate and labor flexibility in order to establish the dependency relationships between its indicators. Methodology. A non-experimental, cross-sectional and correlational study was carried out with a non-probabilistic sample selection of 300 employees from central Mexico. Results and conclusions. The labor climate determines the flexibility, although the most recent literature warns that rather the climate mediates the relationship between the flexibility policies on staff turnover, the informal salary and the absence of benefits. Research lines are recommended concerning the incidence of leadership styles in the variables in question.
\end{abstract}

Key words: flexibility, climate, leadership, rotation, salary.

\title{
Estructura factorial exploratoria clima y flexibilidad laboral
}

\section{Resumen}

Objetivo. El clima laboral ha sido estudiado como un área inherente al liderazgo. En el caso del que se distingue por su comunicación y motivación vertical, el ambiente de trabajo ha sido considerado como un factor determinante de la flexibilidad en términos de condiciones, salarios y beneficios. En este sentido, el objetivo de este documento ha sido explorar las dimensiones del clima y la flexibilidad laboral para establecer las relaciones de dependencia entre sus indicadores. Se realizó un estudio no experimental, transversal y correlacional con una selección de muestras no probabilística de 300 empleados del centro de México. El clima laboral determina la flexibilidad, aunque la literatura más reciente advierte que más bien el clima media la relación entre las políticas de flexibilidad sobre la rotación de personal, el salario informal y la ausencia de beneficios. Se recomiendan líneas de investigación sobre la incidencia de los estilos de liderazgo en las variables en cuestión.

Palabras clave: flexibilidad, clima, liderazgo, rotación, salario. 


\section{Introduction}

7 he working environment for the purposes of this paper, refers to tasks, support s and innovations. In that sense, it is determinant

of labor flexibility, which means informality in the labor force is no longer dependent on an institutional or organizational to diversify their options, commitments, roles and satisfactions opportunity.

In this way, flexibility and climate are factors that emerge from economic policies and institutional as well as organizational strategies. The labor flexibility supposes a multifactorial context that the present work specifies in order to establish its psychological determinants. The economic crises and the technological advances that affected the organizations during the 20th century, in central countries and peripheral economies, gave rise to labor flexibility, but climate change meant the establishment of scenarios and their effects on future production (Piedrahita, Angulo \& López, 2013).

In this way, labor flexibility is indicated by 1) legislation adjusted to unemployment, subsidies and informal vacancies; 2 ) precarious conditions in terms of selection, training and training reflected in the reduction of salaries; 3) the unfair competition and the monopoly supposed an increase of the demands and the decrease of the quality of the processes and products; 4) export strategies sponsored by the State and specialized labor willing to work long hours with low income; 5) energy crisis and its effect on the maquiladora industry, mainly the automotive industry that encouraged mass production without quality control; 6) the contraction of public investment and massive unemployment that meant the pauperization of jobs; 7) proliferation of power groups as a barrier to entrepreneurship and innovation that enhanced mass production without quality; 8) state intervention that exacerbated compensations for illnesses and accidents, as well as unemployment insurance that led to the entry of unskilled labor; 9) public policies that generated poverty, pollution and agglomerations of workers in a single industrial sector; 10) corporate, union and state pacts that produced corruption, inequality and Sabotage mobilization, strikes, boycotts, confrontations, meetings.

However, in the period from 1945 to 1973 growth was not only centralist, but also legitimized the rector of the State and inhibited the participation of academic and social sectors in local and sustainable development (Casas, 2003).

The ineffectiveness of the state model meant the emergence of informal sectors that demanded clientelist public services, while the productive sectors were inhibited by the protectionist and trade union bureaucracy (Abreu, 2002). 
Consequently, deregulatory measures of worker-employer relations were associated with the dismantling. It is a change of state management to a personalized selection of the labor force, the substitution of machinery operated by groups and groups to automated technologies that, not only allowed to extend the working day, but also transformed it into continuous and permanent, opening the possibility of employment of unskilled and low-paid personnel, thus subcontracted for a short period (Alonso, 2008).

In this way, the competition between the organizations that replaced the parastatals and the emergence of companies in areas of specialization and innovation subsequent to the technological revolution, mainly informational, has generated a labor demand for jobs that is estimated at $40 \%$ did not exist five years (Awargala, 2009).

If we consider that occupational changes obey different dimensions, then it will be possible to see a future scenario in which occupations are presented according to economic, political, social, union, educational, scientific and technological structures (Salamat, Zahira \& Mustafa, 2013).

However, in a methodological sense, the analysis of labor flexibility is not limited to sociohistorical, economic, political, labor, trade union, scientific or technological causes, but also in prospective terms, the academic dimension is necessary (López, 2001).

In this sense, the establishment of informal dimensions with respect to formal ones supposes the incorporation of the dimensions used, but with criteria and indicators related to organizations, employers and jobseekers (Guillén, 2007).

Informal companies are distinguished from formal enterprises based on (1) the size of employment and, or (2) State/registration of the company and employees. These limits are defined on a national basis. In India, companies with less than 12 employees are defined as informal. The works that, by definition, do not exist: the cells in dark gray. Jobs that exist but are not informal: cells in light gray. Employment in the informal economy, informal employment and informal employment outside economy casual (Awargala, 2009).

In this way, the flexibility to be circumscribed to the informality and formality derived from the sociohistorical, economic, political and organizational dimensions, highlight the prospective approach that would be indicated by the degree of scientific and technological innovation that organizations would adopt depending on the contexts reviewed (Castro, 2006).

The prospective of labor flexibility, understood as a probable scenario for the production of knowledge according to technological development purposes applied to the quality of processes and products, entails some expected consequences from the period 2020-2060. 
This is a scenario in which migration would reach a shared limit with the level of productivity that began to be observed since 2015, but whose antecedents go back to 1950 when the Welfare State was consolidated and the entrepreneurial crisis began, innovation, productivity and competitiveness (Peschner \& Fotakis, 2013).

The economic dependency ratio is the quotient of the total population over the economically active population (20 to 64 years).

Regarding the educational consequences, mainly in terms of occupational specialization, the trend that was observed in 2010 not only prevails for the economically active population, but also exacerbated in the year 2030 to estimate the asymmetries between the difficulties of employment (Kundu, 2007).

In other words, an increase in occupational skills corresponds to a reduction in elementary jobs. In this sense, those who do not have a high level of specialization and knowledge updating are close to unemployment, although those with postgraduate degrees do not guarantee formal employment (Bautista et al., 2016).

Opportunities and capabilities, from the logic of occupational flexibility, are factors of gender equity. As of the year 2030 not only is expected an occupational parity between men and women, but also it is assumed that the degree of education-training will allow to observe an equal distribution in positions and responsibilities of leadership (Peschner \& Fotakis, 2013).

The indicators related to the level of migratory selectivity, education and training will see equity scenarios in the period from 2020 to 2040, but asymmetric after this period of time given the level of competitiveness and technological dependence of the organizations (Maruco, 2012).

The specification of a dependency relationship model consists in the design of the trajectories of incidence among the variables related to labor flexibility over performance (Adenike, 2011).

In this sense, the literature warns that the reduction of flexibility in the field of occupational health involves the incidence of variables such as quality of life, subjective well-being, work culture and organizational climate - empathy, trust, entrepreneurship, innovation, productivity, competitiveness (Carreón, 2016).

However, the literature also notes the influence of stress -depersonalization, exhaustion, frustration- on well-being and cultureorganizational climate. In this way, resilience emerges as a personal, group and organizational response to the threats and risks posed by the implementation of labor flexibility in organizations and institutions (Luna, 2003). 
In the case of health and educational institutions, the stress associated with resilience generates absorption, dedication and invigoration (Hermosa, 2006).

These are three factors that distinguish individuals, groups and organizations that not only develop a resilience, butalsogenerateopportunities and abilities linked to occupational satisfaction (Meagher, 2003).

Although the literature envisages two explanatory trajectories to the impact of flexibility on performance, in the present work a third route is proposed that will go from flexibilization to despair and hyperopia (Morales, 2002).

Despair has been documented as an emotional state in which workers resign not only to their working conditions, but also to their work and family environment. It is a process in which violence is assumed as an inescapable factor from the search for work to the routine of work (Omar, 2010).

In the case of hyperopia, it is considered an emotional evasion that begins with thejustification of working conditions before labor flexibility and culminates with the acceptance of dismissals or sanctions distant from basic human rights and close to exploitation (Peschner \& Fotakis, 2013).

Therefore, the model would include three explanatory routes of the effects of flexibility on worker performance (García, Bustos \& Carreón, 2017).

It is possible to appreciate that, in any of the cases, the flexibilization produces satisfaction. If you consider the trajectory that begins with the flexibilization, continues with commitment, entrepreneurship, and innovation and culminates with satisfaction, then it is an optimistic scenario in which human relationships and technological advances are combined to reduce labor burdens, increase wages and, above all, produce an identity of the worker towards the organization (Ramírez, 2005).

However, the path that begins with the flexibilization, continues with the depersonalization, despair, and hyperopia and culminates with the satisfaction of an individualized process in which the worker is dedicated to produce without considering the social responsibility of their performance (Carreón, García, Morales \& Rosas, 2013).

Therefore, in the first trajectory a virtuous circle is reflected and in the second route an opposite circle, where satisfaction exists, but reduced to its minimum expression (Vargas, 2011).

The prospective of occupational flexibility seems to show a correlation between scientific and technological advances with respect to the increase in demands for the quality of processes and products. From this relationship, opportunities and capabilities seem to be guided by criteria of specialization and updating of knowledge (Chauhan, 2014). 
This implies social, organizational and personal consequences close to unemployment, exclusion and stress of migrant workers with elementary knowledge and skills, but in the case of those with postgraduate degrees, there is no guarantee of formal employment (Carreón, Morales, Rivera, García \& Hernández, 2014).

The development of a society depends, in principle, on the capacity of its members, individually and in groups, to generate wealth: valuable goods and services in a market system (local, national, regional, international, global).

On the one hand, we can consider work as the way to feel useful, to learn, to grow intellectually and socially or as a need of the soul, a certain contact with reality, truth, the beauty of the universe and with the eternal wisdom of its disposition. No doubt this is a scenario in which most would like to feel and possibly be satisfied. A second scenario, where a few coordinate and command and others that obey and execute, where the subordinate almost plays the role of an activity thought by the intelligence of those few, where each task is the execution of an order, and the worker initiative is left aside, in these circumstances it is almost certain that nobody would want to work, however, this type of scenario is more common to find it in most Mexican companies (Carreón et al., 2016).

This, together with the scarcity of resources, the attention of companies to survival and adaptation to the crisis to the detriment of workers' concerns, or the need to increase productivity with tighter structures are factors that directly affect the labor quality of the worker (Carreón, Hernández, Quintero \& García, 2017).

On the other hand, to the extent that companies offer equity and justice in the treatment of all their employees and encourage a climate oriented to promote the quality of service, then the company and the welfare become compatible. Remember that people have individual, group and organizational behavior, in that same dimension, individual, group and organizational results are obtained. Therefore, people need organizations to meet their needs and organizations need people to function and obtain their results (García, Carreón \& Bustos, 2012).

It is important to delve into the knowledge of the Organizational Climate to change, generate or provoke more humanizing work environments or in other words healthy climates; where all the members of the organization, in spite of their particularities, can collaborate and cooperate with fewer problems. However, it would seem irrelevant primary factor to consider climate study, measurement and monitoring enterprises, particularly MSMEs (García et al., 2017). 
The organizational climate is not a buzzword that attracts attention as others, however, falls under the category of terms that refer to realities that are always present and do not go out of fashion as motivation, job satisfaction, absenteeism, performance, job design, development or quality of working life; but they will not appear in the inventory of managerial fashions such as: benchmarking, empowerment, outsourcing, outplacing or quality (Carreón et al., 2016).

Some productivity problems can be solved in part with capital investments, with restructuring programs or by hiring quality experts, but the Organizational Climate, he emphasizes, has deep implications and obvious relationships with issues of productivity, quality, efficiency, the success, and the supervision of the company and with the managerial task (Carreón, Hernández, Bustos \& García, 2017b).

In addition, the study of culture and climate is important for the field of industrial and organizational psychology because these constructs provide a context for studying organizational behavior, since the social and symbolic processes associated with the emergence of culture and the climate influences both individual and group behaviors (Carreón et al., 2015).

The first studies on climate -elaborated to study at that time the psychological climate- were made in the thirties. The concept of a psychological atmosphere was coined, as an empirical reality and whose existence is demonstrated in the same way as any fact of the physical world, that is, measurable, modifiable, etc. In this same line of thought are the organizational climate is a set of enduring characteristics that describe an organization, distinguish it from another and influence the behavior of the people who form it (Carreón, 2016).

However, as a background, the behavior of workers in the organization is the result of the administrative behavior and the organizational conditions they perceive, as well as their information, their perceptions, their hopes, their capacities and their values, that is, for the workers what counts is the way they see things and not the objective reality (García, Carreón \& Bustos, 2017).

In the field of business administration and industrial / labor psychology, its definition and use refer to a process of sharing meanings by members of an organization that is attributed to events, policies and procedures of experiences and behaviors according to the rewards, support and expectation (García et al., 2016).

From the above, in the literature it is observed cite labor climate, atmosphere or work environment, or organizational climate and the factors that compose it are diverse, that is, it is a multi- dimensional construction or concept, in which attention is paid to variables and internal 
factors of the organization that affect the behavior of the individuals in the organization; Their approach to these variables is through the perceptions that individuals have of them (García, Carreón, Hernández, Bautista \& Méndez, 2012).

Despite the difficulties facing many companies, referring to the Spanish but similar to the Mexican context, consideration of the needs, goals and aspirations of workers with organizational objectives is a key aspect in achieving some organizations productive and healthy and the maintenance of the quality of working life (García et al., 2013).

Thus, for example, they have done so- research relations and leadership behavior, satisfaction and organizational commitment, satisfaction and absenteeism and rotation of staff satisfaction. However, despite the abundant literature on organizational climate and job satisfaction, the agreement between the authors on the content of both constructs is far from complete (García et al., 2014).

Therefore, organizations will have a prevalence to the culture of entrepreneurship, innovation, quality, productivity and competitiveness without considering occupational health as a balancing factor between market demands and internal resources (García et al., 2015).

Which are the axes of the trajectories of dependency relations between the factors related to flexibility and the labor climate in MSMEs in central Mexico?

In virtue of the fact that labor flexibility is a political institutional guideline, the climate of relationships that is built in the small and mediumsized companies of the study will tend to be unfavorable to the climate of tasks, supports and innovations, with leadership emerging as an axis of decision, communication and motivation of personnel.

It is true that The labor climate, being influenced by political flexibility, generates an unfavorable environment for the balance between the demands of the environment and the capabilities of MSMEs, as well as anti-cyclical to the dynamics of organizations, but strengthens the competitive advantages of polyvalence or multifunctionality of the labor force since such sector adjusts not only to employment policies but also adapts to the requirements of the economy 4.0 which is distinguished by its ambivalence and lack of opportunities with which millennial generations learn to develop their skills and knowledge.

\section{Method}

Design. A non-experimental, cross-sectional, exploratory and correlational study was carried out. 
Muestra. It held a nonrandom selection of 300 managers of micro, small and medium enterprises in central Mexico. $67 \%$ are female and the remaining $33 \%$ are male. $32 \%$ completed their baccalaureate studies, $41 \%$ completed their bachelor's degree and the remaining $27 \%$ had postgraduate studies. $45 \%$ declared having an income of less than 3500 pesos per month $(M=3412 S D=$ 23.14), 41\% mentioned that their income ranged between 3500 and 7000 pesos per month $(M=5813 S D=113.24)$ and the remaining $14 \%$ recognized that their income exceeded 7000 pesos per month $(M=8124 S D=234.56) .42 \%$ are in marriage, $24 \%$ in single and the remaining $34 \%$ in free union.

Instrument. The Labor Flexibility of Carreón scale (2017) and the Sanchez Labor Climate Scale (2017) were used, which were built using the Delphi and Lickert technique, assuming that the reagents of the literature could be adjusted to the study context. Provided they were tested in samples similar to those of the study, as well as the inclusion of response options that implied significance intervals in the responses of each reagent.

In the case of labor flexibility, the intentions of the respondents were weighted with respect to informality and staff turnover. This is the case of the reactive "If there were unemployment, it would take turns to have a job opportunity". Each item corresponds to one of the five response options: $0=$ not at all probable, $1=$ very unlikely, $2=$ unlikely, $3=$ somewhat probable, and $4=$ very likely.

Regarding the work environment, the needs and expectations of workers are measured with respect to their leaders, structure and working conditions. Consider the item: "In the face of looming unemployment, the boss's experience is necessary in layoffs." Each reagent includes five options: $0=$ not at all probable, $1=$ very unlikely, $3=$ somewhat probable and $4=$ very likely.

Procedure. The surveys were carried out in the facilities of the MSMEs, with information that the results of the study would not negatively or positively affect their employment status. In addition, the anonymity and confidentiality of the data were guaranteed in writing. The information was processed in Statistical Package for Social Sciences (SPSS by its acronym in English version 20.0). The Cronbach alpha parameter was estimated for the interpretation of the instrument's internal consistency, the adequacy and sphericity statistics of Bartlett and Kaiser Meyer Olkin. To establish the factorial solution, as well as the factorial weights and the percentage of variance explained in an exploratory factor analysis of principal axes with promax rotation in order to establish the validity of the instrument, which assumes a construct that emerges in different contexts and samples. Finally, the correlation parameter was calculated to establish the probable paths s relations put forward factors. 


\section{Results}

The general internal consistency of the instrument (alpha of 0.889 ) exceeds the minimum required (alpha of 0.80 ). This means that the Flexibility and Organizational Climate Scale can be applied in different contexts and samples, yielding results similar to those of the present study (see Table 1).

In fact, if a minimum requirement of 0.70 and a maximum of 0.90 is assumed as the exclusion criterion then none of the items would be excluded because they are in the ideal range of expected consistency.

Table 1. Instrument descriptions

\begin{tabular}{|c|c|c|c|c|c|c|c|c|c|c|}
\hline$R$ & $M$ & V & $C$ & $A$ & $F 1$ & $F 2$ & F3 & $F 4$ & F5 & F6 \\
\hline$R 1$ & 70.14 & 90,469 & 0.463 & 0,885 & & & & & & 0,601 \\
\hline$R 2$ & 70.53 & 90,429 & 0.472 & 0.884 & & & & & & 0,675 \\
\hline$R 3$ & 70.65 & 88,639 & 0,557 & 0.882 & & & & & & 0,683 \\
\hline$R 4$ & 70.23 & 88,178 & 0,595 & 0.881 & & & & & 0,549 & \\
\hline R5 & 70.48 & 88,303 & 0,569 & 0.882 & & & & & 0,673 & \\
\hline$R 6$ & 70.85 & 87.108 & 0,577 & 0.881 & & & & & 0,693 & \\
\hline R7 & 70.40 & 87,483 & 0,598 & 0.881 & & & & 0,671 & & \\
\hline$R 8$ & 69.85 & 92,993 & 0.310 & 0.888 & & & & 0,543 & & \\
\hline R9 & 70.57 & 86,141 & 0,586 & 0.881 & & & & 0,581 & & \\
\hline R10 & 70.11 & 89,204 & 0.615 & 0.882 & & & 0,612 & & & \\
\hline R11 & 70.57 & 91,289 & 0,292 & 0.889 & & & 0,567 & & & \\
\hline R12 & 70.94 & 89,055 & 0.357 & 0.888 & & & 0,673 & & & \\
\hline R13 & 70.57 & 88,910 & 0.453 & 0,885 & & 0,541 & & & & \\
\hline R14 & 70.74 & 90,100 & 0.339 & 0.888 & & 0,543 & & & & \\
\hline R15 & 70.52 & 91,798 & 0.219 & 0,892 & & 0,654 & & & & \\
\hline R16 & 70.47 & 88,472 & 0,540 & 0,883 & 0,623 & & & & & \\
\hline R17 & 70.40 & 89,599 & 0.480 & 0.884 & 0,635 & & & & & \\
\hline R18 & 70.32 & 91,126 & 0.389 & 0,886 & 0,625 & & & & & \\
\hline
\end{tabular}

$\mathrm{M}=$ Measured by removing the value of the item, $\mathrm{V}=$ Variance removing the value of the item, $\mathrm{C}=$ Correlation of the item with the scale, $\mathrm{A}=$ Alpha removed the value of the item. Extraction method: main axes, otation: promax. Adequacy and sphericity $\left\lceil\mathrm{X}^{2}=\right.$ $1864,322(300 \mathrm{gl}) \mathrm{p}=0.000 ; \mathrm{KMO}=0,857 \mathrm{~J} \mathrm{F1}=$ Climate of the leader (alpha of 0.878 and $29.878 \%$ of the total variance explained), F2 = Cli ma of compensation (alpha of 0.870 and $7.973 \%$ of the total variance explained), F3 = Climate of structuring ( alpha of 0,894 and $7,471 \%$ of the total variance explained, $\mathrm{F} 4=$ Working conditions climate (alpha of 0,892 and $5.84 \%$ of the total variance explained), F5 = Flexibility before contingencies (Alpha of 0,782 and $4,996 \mathrm{~d} \%$ of the total variance explained), F6 = Flexibility before risks (alpha of 0.746 and $4.559 \%$ of the total variance explained). All reagents include five response options: $0=$ not at all likely, 1 = very unlikely, 2 = unlikely 3 = somewhat likely, and 4 = very likely.

Source: Prepared with the study data 
The prerequisite for estimating the validity of the instrument is the adequacy and sphericity of the scale, understood as tests that establish the volume of partial correlations and the absence or presence of a factorial identity. Low correlations circumscribed to an entity suggest that analyzes are not recommended to establish the dimensions or factors.

In this way, the adequacy and sphericity $\int_{\chi} 2=1864,322(300 \mathrm{gl}) \mathrm{p}=$ 0,$000 ; \mathrm{KMO}=0.857$ J suggests carrying out the estimation of the factors that the theory recommends.

In the case of validity, understood as the efficiency with which an instrument or scale measures what it intends to measure, based on a confirmatory factorial analysis of principal components with promax rotation it was possible to observe six factors configured by the five theoretical dimensions, although:

The first factor included predominantly the theoretical dimension of relationship with the boss (explaining $29.878 \%$ of the total variance)

The second factor included mainly the theoretical dimension of compensation (explaining $7.973 \%$ of the total variance)

The third factor included preferably the theoretical dimension of the organizational structure (explaining $7.471 \%$ of the total variance)

The fourth factor included essentially the theoretical dimensions of working conditions (explaining 5,584\% of the total variance).

The fifth factor included the theoretical dimension of flexibility before contingencies of the organizational environment (alpha of 0.782 and $4.996 \%$ of the total variance explained).

The sixth factor included the theoretical dimension of the flexibility before risks of the organizational environment (alpha of 0,772 and 4,559\% of the total variance explained).

Based on the reliability and validity analyzes, it is recommended to adjust the observed factors to the theoretical dimensions, suppressing those reagents that are dispersed, or reconceptualizing the dimensions. This would allow the contrast of reflective models of the organizational climate, considering the theoretical dimensions and the empirical factors

In addition, the matrix of correlations shows that there are positive and significant relationships among the five factors, evidencing the possibility of a reflective structure of the organizational climate as a secondorder factor (see Table 2). 
Table 2. Correlations and covariations between the factors

\begin{tabular}{|c|c|c|c|c|c|c|c|c|c|c|c|c|c|c|c|}
\hline & M & $\mathrm{S}$ & $\mathbf{N}$ & F1 & F2 & F3 & F4 & F5 & F6 & F1 & F2 & F3 & F4 & F5 & F6 \\
\hline F1 & 29.7756 & 5.05445 & 205 & 1,000 & & & & & & 1,896 & & & & & \\
\hline F2 & 22.4078 & 4.25856 & 206 & $0.799 * *$ & 1,000 & & & & & 0,564 & 1,897 & & & & \\
\hline F3 & 17.8349 & 2.83280 & 212 & $0.832 * *$ & $0,744^{* *}$ & 1,000 & & & & 0,671 & 0,672 & 1,804 & & & \\
\hline F4 & 20.3173 & 3.29475 & 208 & $0.690^{* *}$ & $0.837^{* *}$ & $0.657^{* *}$ & 1,000 & & & 0,694 & 0,604 & 0,547 & 1,875 & & \\
\hline F5 & 17.4340 & 2.76237 & 212 & $0.688^{* *}$ & $0.602^{* *}$ & $0.614^{* *}$ & 0.638 & 1,000 & & 0,546 & 0,674 & 0,673 & 0,604 & 1,673 & \\
\hline F6 & 16.2821 & 2,19231 & 219 & 0,561 ** & $0.506^{* *}$ & 0.423 ** & 0.332 & 0.4035 & 1.00 & 0,587 & 0,654 & 0,593 & 0,651 & 0,579 & 1,782 \\
\hline
\end{tabular}

$\mathrm{M}=$ Average of each factor, $\mathrm{DE}=$ Standard deviation of each factor, $\mathrm{N}=$ Number of observations in each factor, F1 = Climate of the leader, F2 = Climate of compensation, F3 = Climate of structuring, F4 = Climate of working conditions F5 = Flexibility before contingencies, F6 = Flexibility before risks. ${ }^{*} \mathrm{p}<0.01$; ${ }^{* *} \mathrm{p}<0.001$; ${ }^{* * *} \mathrm{p}<0.0001$

Source: Prepared with the study data

The adequacy and sphericity $\int \mathrm{X}^{2}=789,577(10 \mathrm{gl}) \mathrm{p}=0.000 ; \mathrm{KMO}=$ 0.833 suggests carrying out the second order factorial analysis.

The factor of second order or organizational climate included each of the five factors, explaining $76.690 \%$ of the total variance, which suggests the contrast of the model from five reflective factors in which the relationship with the boss would be the predominant factor.

Once established factors first and second order, we proceeded to establish the dependency relationships between the factors of the organizational environment as determinants of factors labor flexibility and dimensions relative to contingencies and risks (see Table 3).

It is possible to observe that the organizational climate, as a second order factor formed by the relationship with the boss, compensation, structure, compensations and motivation are determinants of labor flexibility as a second-order factor indicated by the isolation, overload, complicity and queries $\left(\beta=.634, \mathrm{p}=.000 ; \mathrm{R}=0.634, \mathrm{R}^{2}=0.402, \mathrm{R}^{2}{ }_{\mathrm{jd}}=0.399\right)$.

Regarding the other dependency relations, low values tend to spurious relationships and also not significant.

Once established multiple regressions, a model of dependency relationships paths where you can observe established climate leader as the determinant of labor flexibility (0.58), followed by climate of working conditions (0.41). In the case of the organizational climate, the climate of compensations was its main determinant $(0.48)$ and the labor condition, the relationship with the leader was its determinant (0.86).

Once the six first-order factors and their linear relationships were established, we proceeded to observe their structure in order to establish the determining trajectories of labor flexibility (see Figure 1). 
Table 3. Dependence relations between the factors of the organizational code and labor flexibility

\begin{tabular}{|c|c|c|c|c|c|c|c|}
\hline Model & Hypothesis & Trajectory & $B$ & Sig & $R$ & $R^{2}$ & $R^{2}{ }_{\text {adjisted }}$ \\
\hline \multirow{3}{*}{ I } & $1^{3}$ & Organizational climate è Labor flexibility & 0.693 & 0.009 & 0.693 & 0.409 & 0.303 \\
\hline & $1 \mathrm{~B}$ & Organizational climate è Flexibility before risks & 0.644 & 0,000 & 0.634 & 0.488 & 0.384 \\
\hline & $1 \mathrm{C}$ & Organizational climate è Flexibility before contingencies & 0.642 & 0,000 & 0.603 & 0.453 & 0.334 \\
\hline \multirow{3}{*}{ II } & $2^{\mathrm{a}}$ & Leader's climate è Labor flexibility & 0,570 & 0,260 & 0,550 & 0,323 & 0.207 \\
\hline & $2 b$ & Leader's climate è Flexibility before risks & 0,542 & 0,000 & 0,542 & 0.395 & 0.291 \\
\hline & $2 \mathrm{C}$ & Leader's climate è Flexibility in the face of contingencies & 0,592 & 0,000 & 0,592 & 0.342 & 0,238 \\
\hline \multirow{3}{*}{ III } & $3^{\mathrm{a}}$ & Remuneration climate è Labor flexibility & 0.470 & 0,000 & 0.491 & 0,241 & 0.121 \\
\hline & $3 \mathrm{~b}$ & Remuneration climate è Flexibility before risks & 0.452 & 0.320 & 0.419 & 0.270 & 0.150 \\
\hline & $3 c$ & Remuneration climate è Flexibility before contingencies & 0.412 & 0.202 & 0.401 & 0.240 & 0,115 \\
\hline \multirow{3}{*}{ IV } & $4^{\mathrm{a}}$ & Structures climate è Labor flexibility & 0.331 & 0.002 & 0.383 & 0.143 & 0,084 \\
\hline & $4 \mathrm{~b}$ & Structures climate è Flexibility before risks & 0.332 & 0.067 & 0.357 & 0.184 & 0.072 \\
\hline & $4 c$ & Structures climate è Flexibility before contingencies & 0.321 & 0.002 & 0.356 & 0.194 & 0,084 \\
\hline \multirow{3}{*}{ V } & $5^{\mathrm{a}}$ & climate è Flexibility before risks & 0.204 & 0,000 & 0,232 & 0.003 & 0.005 \\
\hline & $5 \mathrm{~b}$ & climate è Flexibility before contingencies & 0.201 & 0,000 & 0,212 & 0.001 & 0.001 \\
\hline & $5 c$ & climate è Labor flexibility & 0,234 & 0,000 & 0,234 & 0.002 & 0.009 \\
\hline
\end{tabular}

$\beta=$ parameter of dependency ratio between a dependent variable and another independent variable, both in relation to other determining variables. Significance $=$ degree of attribution error of the dependency relation, $\mathrm{R}$ = statistic of dependence relation, $\mathrm{R} 2$ = statistic of dependency relation squared, adjusted R 2 = statistic of dependence ratio squared and adjusted, reflective of the total variance explained for each model.

Source: Prepared with the study data

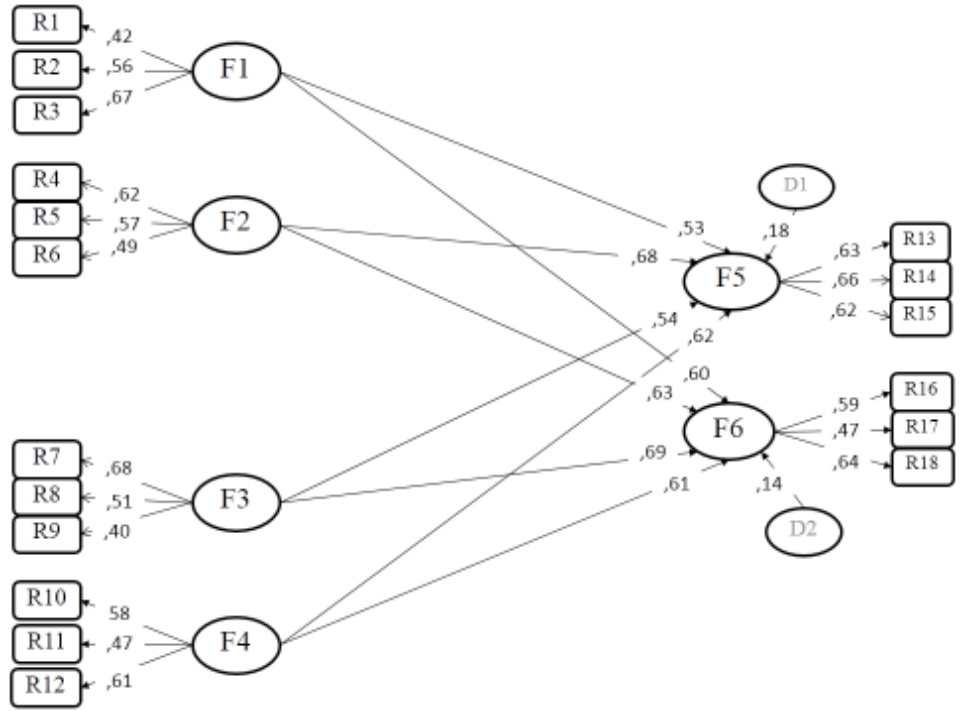

Figure 1. Structural Equation Modelling

F1 = Climate of the leader, F2 = Climate of compensation, F3 = Climate of structuring, F4 = Climate of working conditions F5 = Flexibility before contingencies, F6 = Flexibility before risks: ç relations between error or disturbance and factors or indicators

Source: Elaborated with data study 
Finally, the adjustment parameters $\int_{\chi}^{2}=5.552(2 \mathrm{gl}) \mathrm{p}=0.062$; GFI $=0.974 ; \mathrm{NFI}=0.964 ; \mathrm{IFI}=0.977 ; \mathrm{CFI}=0.972 ; \mathrm{RMSEA}=0.229-$ show the adjustment of the theoretical structure with respect to the weighted observations.

\section{Discussion}

In relation to the theoretical, conceptual and empirical frameworks, which highlight leadership as a factor linking climate and labor flexibility, establishing that bidirectional communication and intrinsic motivation are indicative of levels of external demands and internal resources, weighting of equilibrium $s$ when establishing a climate of relationships, tasks, supports and innovations with respect to conditions, rotations, salaries, rewards and benefits in situations that are increasingly contingent on the market. The present work, rather proposes that leadership is an intangible capital in terms of skills, knowledge and experiences, which will determine not only the climate but also motivate staff to such a point that a climate of relationships will coexist with a rotation of functions and decrease of salaries in situations of unemployment.

However, thetype of non-experimentalandexploratory study, aswell as the type of non-probabilistic and rather intentional sampling selection limit the results of the study to the sample surveyed. It is recommended to carry out an experimental study with a probabilistic selection in order to be able to contrast the hypotheses in a different context and sample from the present work.

As for the findings of Carreón (2017) where they warn that market contingencies are indirect determinants of the work climate and the performance of organizations. In other words, to the extent that the policies of business development and microfinance encourage productivity, leaders are committed to carrying out strategies that, due to their degree of improvisation, involve unidirectional communication and motivation in remuneration that allows them to live up to the demands of the market.

In such a scenario, the labor climate is a mediating factor of economic, productive and employment policies, but leadership prevails in the labor relations climate, with flexibility being a distinctive feature of the environment rather than of the organization or groups. of work inside of them.

However, Carreón \& García (2017) warn that the influence of leadership in vocational training not only implies a work environment that can be oriented towards labor flexibility, but also implies the prevalence of 
the climate of relationships with other types of work environments. Tasks, goals, innovations and supports, which suppose a traditional leadership that guides the employees or subordinates, at the same time as it motivates the talents and intellectual capitals.

Iftheworkingenvironmentisaresultoflocalpoliciesand simultaneously determines a type of informal performance and rotation, then explain and anticipate the Exit meeting the organizations in establishing a scenario of trust and expectation that could influence constant professional training, specialized training and self-motivation to achievements, which explain the type of leadership for medium-sized companies.

It is necessary to carry out the contrast climate organizational and labor flexibility in groups of micro, small and medium enterprises in order to establish the organizational determinants and their influence on the similarities and differences between MSMEs when weighing their performance, commitment and satisfaction. Such a design could also be extended to the groups of sex, age, income and marital status to elucidate the profiles that would adjust to informal and austere working conditions.

\section{Conclusion}

The contribution of this work to the state of the question lies in the establishment of the reliability and validity of an instrument that measures the climate and labor flexibility, but the type of design and sample selection imitate the findings in the study sample.

The statistical properties of the instrument indicate that the labor climate is more multidimensional than the flexibility since, it seems to be a mediator of the policies of local impulse on the opportunities and the informal labor capacities. This reflects a validity of context that the instrument in question could develop further in samples and scenarios different from the study one.

In addition, in relation to other variables such as leadership, the instrument can be extended in order to incorporate leadership as a determinant of climate and labor flexibility, main findings reported in the literature consulted. 
Exploratory factorial structure climate and labor flexibility

\section{References}

Abreu, M. (2002). Prospective of stock exchange organizations in Mexico. Denarious. 5, 31-54. Adenike, A. (2011). Organization climate as a predictor of employee job satisfaction. Business Intelligence Journal, 4, 151-166.

Alonso, P. (2008). Comparative study of job satisfaction in the administration staff. Journal of Work and Organizational Psychology, 24, 25-40.

Awargala, R. (2009). An economic sociology of informal work: the case of India. Research in the Sociology of Work, 18, 315-342. DOI: 10.1108 / S0277-2833 (2009) 0000018015.

Bautista, M., Delgado, M. A., García, C., Valdés, O., Hernández, G., Castro, F. J.,... Trujillo, K. V. (2016). Contrasting a model of organizational culture in community health centers before the dissemination of information on HIV / AIDS from social work. Teaching and Research in Psychology, 21 (3), 248-255.

Carreón, J. \& García, C. (2017). Specification of a model for the study of vocational training and job. International Journal of Advances in Social Science and Humanities, 5 (6), 13-18.

Carreón, J. (2016). Human Development: governance and social entrepreneurship. Ciudad de México, Mexico: UNAM-ENTS.

Carreón, J., Bautista, M., García, C., Hernández, G., Sandoval, F. R., Pérez, G.,...Valdés, O. (2016). Reliability and validity of an instrument that measures perceptions of occupational health in migrants from Huehuetoca, State of Mexico. Obets, 11 (2), 569-581.

Carreón, J., García, C., Morales, M. \& Rosas, F. (2013). Labor commitment in the Social Work of the health sector. Invurnus, 8 (2), 15-23.

Carreón, J., Hernández, J., Bustos, J. M. \& García, C. (2017a). Reliability and validity of an instrument that measures the commitment of social workers in healthcare institutions. Crossroads, 26, 69-86.

Carreón, J., Hernández, J., Bustos, J. M. \& García, C. (2017b). Business promotion policies and their effects on risk perceptions in coffee growers in Xilitla, San Luis Potosí, central Mexico. Poiesis, 32, 33-1.

Carreón, J., Hernández, J., Quintero, M. L. \& García, C. (2017). Reliability and validity of an instrument that measures organizational collaboration in a public university in Huehuetoca, central Mexico. Invurnus, 12(2), 9-17.

Carreón, J., Morales, M., Rivera, B., García, C. \& Hernández, J. (2014). Migrantentrepreneur and trader: State of knowledge. Tlatemoani, 15, 1-30.

Casas, R. (2003). Approach for the analysis of networks and knowledge flows. In M. Luna. (Coord.), Knowledge itineraries: academic forms and content. A network approach (pp. 19-50). Barcelona, Spain: Anthropos.

Castro, A. (2006). Implicit theories of leadership, context and driving ability. Annals of Psychology. 22, 89-97.

Chauhan, G. (2014). Development and validation of resource flexibility measures for manufacturing industry. Journal of Industrial Engineering and Management, 7(1), 21-41. DOI: 10.3926 / jiem.655.

García, C., Bustos, J. M. \& Carreón, J. (2017). Exploratory dimensions of social and labor stigma. A Delhi study with undergraduate students. Eureka, 14(1), 55-68.

García, C., Carreón, J. \& Bustos, J. M. (2012). Socialization and labor commitment in social workers of public and private institutions. Humanism and Social Work, 11, 177-192.

García, C., Carreón, J. \& Bustos, J. M. (2017). The occupational health of elderly people in an electoral context of a locality in the center of Mexico. Doxa, 7(12), 36-49.

García, C., Carreón, J. \& Hernández, J. (2014). The professional training of human capital in the civilization of climate change. International Journal of Research in Social Sciences, 10(1), 107-125. 
García, C., Carreón, J. \& Hernández, J. (2017). Limits of occupational health models. Study of adherence to the treatment of asthma in migrant elderly workers of the State of Mexico. Management Vision, 16(1), 103-118.

García, C., Carreón, J., Hernández, J. \& Morales, M. (2014). Contrast of a model of labor commitment in public health centers. University Act, 24(1), 48-59

García, C., Carreón, J., Hernández, J., Bautista, M. \& Méndez, A. (2012). Modeling of sociopsychological variables from the review of the state of the art. Journal of the Faculty of Social Work, 28(28), 13-60.

García, C., Carreón, J., Hernández, J., Bustos, J. M., Bautista, M., Mendez, A.,... Morales, M. L. (2013). Compromiso laboral en el trabajo social del sector salud. Medicina Salud y Sociedad, 4(1), 39-58.

García, C., Carreón, J., Hernández, J., Carbajal, C., Quintero, M. L., Sandoval, F.R.,... Valdés, O. (2016). Incidence of micro-financing policies on the perception of coffee entrepreneurship and implications for Social Work. Ehquity, 6, 11-36.

García, C., Valdés, O., Sánchez, R., Elizarraraz, G., Méndez, A. \& Hernández, J. (2015). Differences between Internet entrepreneurs with respect to empathy, risk perceptions and use of technological applications. Prospects in Psychology, 2(1), 68-75.

Guillén, A. (2007). Neoliberal globalization. Ciudad de México, Mexico: UAM.

Hermosa, A. (2006). Job satisfaction and bournout syndrome in primary and secondary school teachers. Colombian Journal of Psychology, 15, 81-89.

Kundu, K. (2007). Development of the conceptual framework of the organizational climate. Vidyasagar University Journal of Commerce, 12, 100-110.

López, E. (2001). Charismatic leadership in organizations? Elements for a reflection on the change in intra- organizational relations. Journal of Social Psychology,16, 97-115.

Luna, M. (2003). The network as a coordination mechanism and knowledge networks. In M. Luna. (Coord.), Knowledge itineraries: academic forms and content. A network approach (pp. 5178). Barcelona, Spain: Anthropos.

Maruco, M. (2012). Burnout syndrome in pediatricians. Analysis of variables that could enhance the appearance and exacerbation of general hospitals. Magazine Academic of Social Sciences, 16, 1-9.

Meagher, M. (2003). Regulatory organizations: perceptions of the academic and business sector about their relationships with a network. In M. Luna. (Coord.), Knowledge itineraries: academic forms and content. A network approach (pp. 259-305). Barcelona, Spain: Anthropos.

Morales, J. (2002). Decay, mortality and organizational experience: strategic management of Mexican organizations in neoliberalism. Denarious, 5, 55-74.

Omar, A. (2010). Transformational leadership and job satisfaction: the role of trust in the supervisor. Liberabit, 17, 129-137.

Peschner, J. \& Fotakis, C. (2013). Growth potential of EU human resources and policy implications for future economic growth. Working Paper European Commission. DOI: 10.2767 / 79370.

Piedrahita, D., Angulo, H. \& López, H. (2013). Labor flexibility, conceptual analysis and its incidence in Latin American countries, recent debates. Prospective, 18, 221-242.

Ramírez, H. (2005). Knowledge as a competitive weapon between companies. 117-135. In P. Dorantes., E. Espinosa., I. Guillén., F. Martínez., L. Ureña. \& C. Valladares. (Coords.). Analysis, evaluation and management perspective. Ciudad de México, Mexico: UAM.

Salamat, N., Zahira, N. \& Mustafa, L. (2013). The impact of organizational climate on teachers job performance. Educational Research, 2(1), 71-82 http://dx.doi.org/10.5838/ erej.2013.21.06.

Vargas, J. (2011). Organization of work and job satisfaction: a case study in the footwear industry. Magazine Electronics Nova Scientia, 4, 172-204. 